\title{
Sensory Profile and Consumer Acceptability of Ziziphus mauritiana and Processing Product in Savannah Region of Cameroon
}

\author{
Charles Touwang ${ }^{1}$, Pierre Biyanzi ${ }^{1}$, Robert Ndjouenkeu ${ }^{1 *}$, Géneviève Fliedel ${ }^{2}$, \\ Aurélie Bechoff ${ }^{3}$, Keith I. Tomlins ${ }^{3}$ and Dominique Pallet ${ }^{2}$ \\ ${ }^{1}$ Department of Food Science and Nutrition, University of Ngaoundéré, P.O. Box 455, Ngaoundéré, \\ ${ }^{2}$ International Agronomic Research Centre for Development (CIRAD), 34398, Montpellier, Cameroon. \\ France. \\ ${ }^{3}$ Natural Resources Institute (NRI), University of Greenwich, UK.
}

\begin{abstract}
Authors' contributions
This work was carried out in collaboration between all authors. Authors CT and PB conducted the field work (sample collection, sensory and consumer analyses). Author RN designed the work, co-

supervised the field work and wrote the first draft of the manuscript. Author GF coordinated the sensory evaluation and consumer test. Authors KIT and AB supervised the data analysis of sensory and consumer tests. Author DP coordinated the work in the framework of after project and validated the protocols

Article Information

DOI: 10.9734/JSRR/2015/14515 Editor(s):

(1) Lesław Juszczak, University of Agriculture in Krakow, Poland. Reviewers:

(1) Anonymous, Instituto de Pesquisa Energéticas e Nucleares, Brazil. (2) Anonymous, Université Paul-Sabatier, Toulouse, France. Complete Peer review History: http://www.sciencedomain.org/review-history.php?iid=746\&id=22\&aid=6996
\end{abstract}

Original Research Article

Received $1^{\text {st }}$ October 2014

Accepted 27th October 2014

Published $18^{\text {th }}$ November 2014

\section{ABSTRACT}

Aim: Ziziphus mauritiana is an endemic fruit spread in the savannah region of Cameroon. The fruit, locally called Jaabi, is harvested dry and consumed as such or processed into a local cake named Yaabande, using three baking techniques (sun drying, steam baking and stifle baking). The aim of the study is to characterize the sensory profile and consumer acceptability of the fruit and its processed product, in order to evaluate the determinant of their quality attributes as influenced by ecotype, origin and processing method.

Place of Study: The study was carried out in the Department of Food Science and Nutrition, 
University of Ngaoundéré, Cameroon.

Methodology: Physico-chemical analysis, sensory profile by a semi trained panel, and consumer acceptability of the fruits and their processed products were undergone through collection of two ecotypes of the fruit (Jaabi Dakamji and Jaabi Lammuji) from four areas (Garoua, Mora, Maroua and Mokolo). African and non African consumers were used for the consumer tests.

Results: Sensory analysis differentiated the fruits by ecotype and origin, with the Dakamji ecotype appearing more homogeneous whatever the origin. The processed cakes differed mainly by their texture, depending on the baking method, with chewing texture for sun processed method, while samples from steam and stifle baking were more firm in mouth. Meanwhile, all samples were acceptable at comparable level corresponding to pleasant character, the sweet taste constituting the main criteria for consuming the products, both for African and non African consumers. In this respect Dakamji ecotype was sweeter, due to its higher sugar content, while the sweetness of Lammuji ecotype was lowered by its acid content.

Conclusion: Jaabi and Yaabande samples are globally acceptable by consumers, whatever the origin and the variety. Development of products emphasising the original taste of Jaabi and standardisation of processing techniques appear as some main aspects of the market development of the fruit.

Keywords: Ziziphus mauritiana; Jaabi; Yaabande; sensory profile; consumer acceptability.

\section{INTRODUCTION}

Jaabi is, in Cameroon, the local name of the fruit of jujube tree (Ziziphus mauritiana), an endemic tree, largely spread in the savannah region of the country. The fruit is harvested dry and mainly consumed as side-dish. Its pulp is also pounded into flour which is then processed into a local cake called "Yaabande". The processing of the fruit into Yaabande represents a form of conservation of the product which is consumed throughout the dry season, and even thereafter. In spite of the fact that Jaabi and Yaabande are currently sold on local market during the harvesting season, these products have not attracted significant scientific interest. Jaabi is then one of the underutilized plant species which has not received any benefit in terms of control of the cropping system or development for markets, contrary to the Asian practices where the jujube fruit is valorized into different foods and pharmaceutical products, with market, technology and quality development [1].

Out of information provided by Noyé [2] on Yaabande, no scientific study exists on Jaabi. It is, in fact, evident that understanding the local production and processing systems of jaabi, in relation with its characteristics and quality, constitutes one of the main steps to fulfill, in order to set up technology and market development of the product.

In this respect, a survey of Jaabi production, processing, trading and consumption systems in savannah area of Cameroon has identified two consumable ecotypes of Ziziphus mauritiana locally called Jaabi Lammuji and Jaabi Dakamji, and has shown that the processing practice, exclusively traditional, is the panacea of women who use steam cooking, sun drying or stifle cooking to bake the cake. The quality attributes of the products, as perceived by operators and consumers are based mainly on the maturity of Jaabi grain, and the color and texture of the cake [3].

Diversity of processing practices and even diversity of Jaabi varieties results in diversity of appreciation and quality of the products on the market. Since consumer acceptance is important in marketing strategy and economic viability for product development [4], the present study explore the sensory profile and acceptance of Jaabi and Yaabande harvested and processed in the savannah regions of Cameroon, assuming hypothetically that Jaabi variety and origin, and processing practices influence the acceptability of products.

\section{MATERIALS AND METHODS}

\subsection{Sampling of Jaabi and Yaabande}

Jaabi and Yaabande were collected in four areas of the savannah region of Cameroon (Garoua, Mora, Maroua and Mokolo), between December 2011 and January 2012 (Fig. 1). For each sampling area, the two ecotypes of consumable Jaabi (lammuji and dakamji) were collected. In addition, Yaabande processed from each ecotype, according to the processing method available locally was also collected. A Yaabande 
sample of mixed Jaabi origins was also collected from a processor in Garoua. The processing methods identified included: Molding of the flour in small calabash or wrapping in vegetable leaves, followed by steam cooking (using traditional steam $r$ [3], sun drying (exposition of the molded product under sun for one or two days) or stifle cooking (by introducing samples wrapped in leaves under hot ash).
Both harvesters and processors in each sampling area were selected and sensitized in order to guarantee the original quality of collected products. A total of 18 samples were collected, made of 8 samples of Jaabi grains (2 ecotypes and 4 origins) and 10 samples of resulting Yaabande (Table 1).

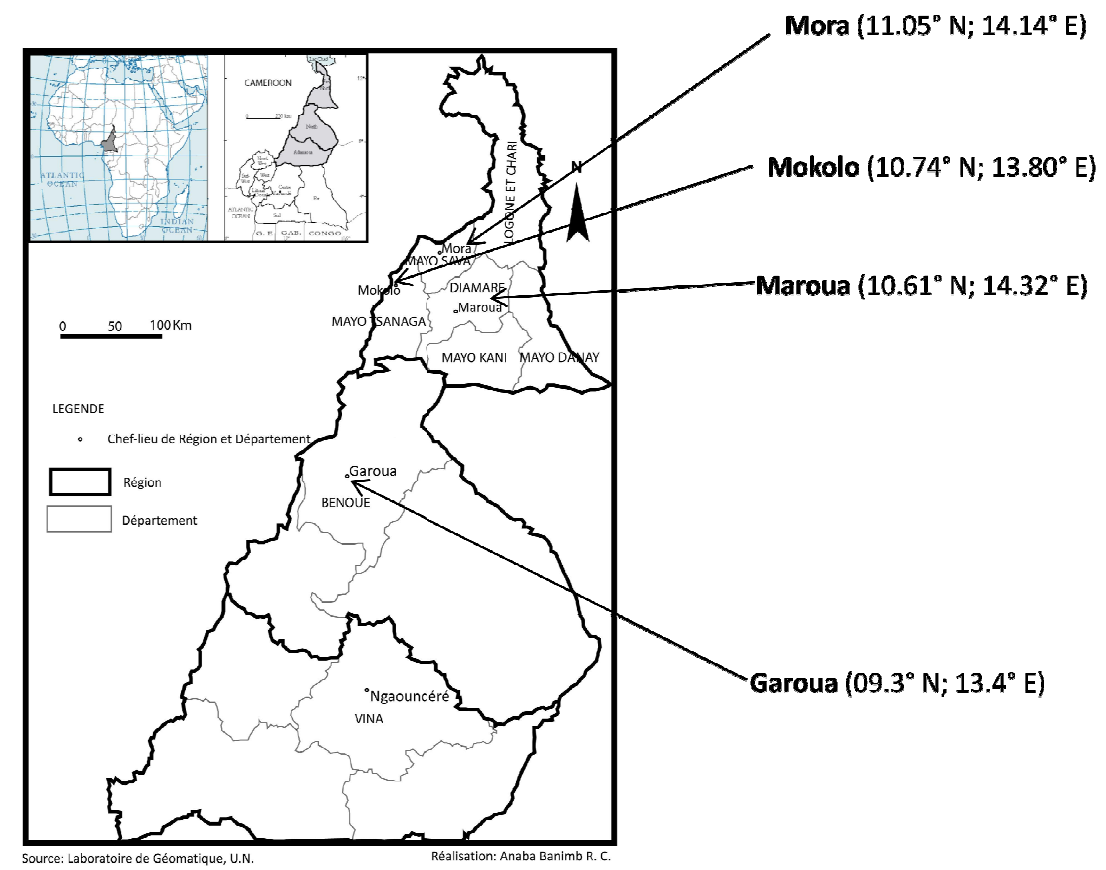

Fig. 1. Sampling areas of Jaabi and Yaabande

Table 1. Characteristics of collected samples of Jaabi and Yaabande according to variety, origin, and processing method

\begin{tabular}{|c|c|c|c|c|c|}
\hline \multirow[t]{2}{*}{ Jaabi ecotypes } & \multirow[t]{2}{*}{ Origin } & \multirow[t]{2}{*}{ Jaabi codes } & \multicolumn{3}{|c|}{ Yaabande } \\
\hline & & & Steam cooking & Sun drying & Stifle cooking \\
\hline \multirow[t]{4}{*}{ Lammuji } & Garoua & L-Ga & L-Ga-Vapor & & \\
\hline & Maroua & L-Ma & L-Ma-Vapor & & \\
\hline & Mokolo & L-Mk & L-Mk-Vapor & & \\
\hline & Mora & L-Mo & & L-Mora-Sun & \\
\hline \multirow[t]{4}{*}{ Dakamji } & Garoua & D-Ga & D-Ga-Vapor & & \\
\hline & Maroua & D-Ma & D-Ma-Vapor & & D-Ma-Stifle \\
\hline & Mokolo & D-Mk & D-Mk-Vapor & & \\
\hline & Mora & D-Mo & & D-Mo-Sun & \\
\hline Mixed & Garoua & Mix-Ga & Mix-Ga-Vapor & & \\
\hline
\end{tabular}




\subsection{Sensory Evaluation}

Jaabi and Yaabande samples were scored by a semi-trained sensory panel using a modified version of quantitative descriptive analysis (QDA) since standards were not provided $[5,6]$. The panel was composed of university technicians and students (17 people in total for Jaabi tests and 19 for Yaabande tests). Sessions were conducted in a dedicated sensory evaluation room at ambient temperature $\left(22\right.$ to $\left.25^{\circ} \mathrm{C}\right)$. The panellists were previously screened for familiarity with the product. Sensory attributes were generated during a preliminary focus group session guided by the panel leader. These sensory attributes generated are presented on (Table 2).

After a period of training using these attributes, the 8 Jaabi samples and 11 Yaabande samples were tested blind in triplicate by the panel and the order in which they were presented was random. At each session, four samples of Jaabi or Yaabande, coded with 3 figure random numbers, were served either on a white paper or in a white dish, in random order to each panelist, who had to score sensory attributes on a 100 $\mathrm{mm}$ unstructured scale, anchored with terms related to minimum intensity at the left end and maximum intensity at the right end.

\subsection{Consumer Acceptability}

African (116 for Jaabi and 164 for Yaabande) and European (38 for Jaabi and 35 for Yaabande) consumers were interviewed in different locations of Garoua, Maroua and Ngaoundéré towns using the central location method [5]. The locations were hotels, market places, coffee shops, Universities (Ngaoundéré and Maroua).

Five Jaabi samples and four Yaabande samples were selected for consumer testing, based on the results of sensory testing. During acceptability testing, each consumer was invited to taste each Jaabi or Yaabande (presented in random order and coded with three figure random numbers). Consumers were asked to score the acceptability with respect to appearance, taste and overall liking using a ninepoint verbal hedonic box scale which varied from dislike extremely (1) to like extremely (9)[5]. In addition, consumers were asked to justify with their own terms the reason of acceptability of products. Along with the testing, information was elicited from each consumer regarding demographics, education and products consumption and buying. Trained enumerators assisted the consumers when required. The interview procedure (acceptability and the questionnaire) lasted no more than $30 \mathrm{~min}$.

Table 2. Sensory attributes of Jaabi and Yaabande

\begin{tabular}{|c|c|}
\hline Jaabi & Yaabande \\
\hline Appearance & Appearence \\
\hline $\begin{array}{ll}\text { - } & \text { Color } \\
\text { - } & \text { Aspect (smooth, rough) } \\
\text { - } & \text { Defect aspect (spots, holes, dirt...) }\end{array}$ & $\begin{array}{ll}\text { - } & \text { Color } \\
\text { - } & \text { Presence of spots (inside and outside) } \\
\text { - } & \text { Aspect (friable- compact) } \\
\text { - } & \text { Fineness }\end{array}$ \\
\hline Odor & Odor \\
\hline $\begin{array}{ll}\text { - } & \text { Dry fruit odor } \\
\text { - } & \text { Dusty odor } \\
\text { - } & \text { Grilled odor (biscuit, cake, caramel) } \\
\end{array}$ & $\begin{array}{ll}\text { - } & \text { Fruity } \\
\text { - } & \text { Grilled }\end{array}$ \\
\hline Texture & Texture \\
\hline $\begin{array}{ll}- & \text { Skin texture (on crunching) } \\
\text { - } & \text { Global texture (on crunching) } \\
\text { - } & \text { Flesh thickness } \\
\text { - } & \text { Flesh texture (on chewing) } \\
\end{array}$ & $\begin{array}{ll}\text { - } & \text { Firmness } \\
\text { - } & \text { Chewing texture } \\
\text { - } & \text { Fineness }\end{array}$ \\
\hline Taste & Taste \\
\hline $\begin{array}{ll}\text { - } & \text { Sweet } \\
\text { - } & \text { Acid } \\
\text { - } & \text { Fruity }\end{array}$ & $\begin{array}{ll}\text { - } & \text { Sweet (fruit, candy...) } \\
\text { - } & \text { Acid } \\
\text { - } & \text { Biscuit } \\
\text { - } & \text { After taste (Bitterness, astringence, ...) }\end{array}$ \\
\hline
\end{tabular}




\subsection{Physico-chemical Analyses}

Titrable acidity and reducing sugar of Jaabi samples were determined using standard methods $[7,8]$. In addition the pulp mass of fruits was determined by knife removal and weighing of the pulp of 100 fruits.

\subsection{Data Analysis}

All data were treated using XLSTAT Version 2007.8.04 package. The main analyses undergone in this respect were analysis of variance (ANOVA), Principal Component Analysis (PCA), Hierarchical clustering and correlations.

\section{RESULTS AND DISCUSSION}

\subsection{Physico-chemical Characterization of Jaabi}

From physico-chemical point of view, Jaabi samples appear different by ecotype and by origin (Table 3). Dakamji ecotype has higher sugar content, while Lammuji is characterized by higher acidity. This may justify the local names given to the two ecotypes, Dakamji for sweet taste and Lammuji for bitter or acid taste. While titrable acidity of Dakamji is identical whatever the origin, the Lammuji from Garoua is far more acid than all other samples. In the same way, Maroua samples, whatever the ecotype, are characterized by the lowest mass pulp, on the contrary to samples from Mora, which are fleshier.

\subsection{Sensory Profile of Jaabi and Yaabande}

The relationships between the sensory attributes of the products are summarized using Principal Component Analysis (PCA). For the Jaabi fruits, up to $61.77 \%$ of these relationships can be represented by the first two main components (F1 and F2) as shown on (Fig. 2). Texture attributes (global texture, skin texture, flesh texture) and color intensity are positively deployed on F1 axis. F2 component carries positively, aspect (smooth - rough) and dry fruit odor attributes, and negatively, flesh thickness and acid taste. Though the resolution is too low, the graph shows that Jaabi can be differentiated both by its ecotype and origin. Lammuji fruits from Mora (L-Mo) and from Mokolo (L-Mk) are associated to smooth or rough aspect, while the same variety from Garoua is mainly associated to pulp thickness and acidic taste. On the other hand, the Lammuji from Maroua (L-Ma) presents common sensory attributes with the Dakamji ecotype from all regions. In this respect, the Dakamji ecotype from different origins seems more homogenous than the Lammuji ecotype as shown by the sensory profile of each ecotype (Fig. 3). Dakamji ecotype, whatever the origin, is mainly characterized by its dark color, its texture (pellicle, overall fruit and pulp) and its odor (dust or grilled). In general, Dakamji presents higher means for these attributes. It should be noted that sweet and fruity tastes are almost common at relative equal value for the different samples, except for Lammuji Garoua (L-Ga) in which the sweet taste is lowered by high acidity.

The dispersion of Lammuji ecotype with respect to origin may be explained by variability of harvesting conditions of the fruits in the different regions. With regards to this hypothesis, all samples were not harvested at the same moment; thus the difference in the maturity of fruits may results in difference in their taste. In addition, fruits are not harvested from tree. They are harvested by field collection of mature and dry fruits fallen from jujube trees [3]. This practice may justify both the dust odor of fruits and a modification of color and aspect attributes, depending on the time the fruit stays on the earth. The harvesting and manipulation conditions may also explain the presence of defection on Jaabi fruit. In this respect, samples from Mokolo are more concerned, with the highest means for this attribute.

Correlations between all sensory attributes, including physicochemical data, indicate that in Dakamji ecotype (Table 4), the grilled odor of the fruit is correlated positively with the color intensity of the fruit and its dry fruit odor, and negatively with the pulp mass; while the latter is negatively correlated to dry fruit odor. For Lammuji ecotype (Table 5), color intensity, grilled odor and skin texture are positively correlated; while dry fruit odor is positively linked to sweet taste and negatively to acid taste. In addition, Lammuji sweet and acid tastes are inversely related, the acid taste being due to high acidity of the product. 
Table 3. Some physico-chemical characteristics of Jaabi samples

\begin{tabular}{lllll}
\hline Jaabi ecotypes & Origin & Pulp mass (g) & Soluble sugar (\% DM) & $\begin{array}{l}\text { Titrable acidity } \\
\text { (g citric acid/100 DM) }\end{array}$ \\
\hline Lamouji & Garoua & $0.28 \pm 0.02$ & $9.80 \pm 0.30$ & $7.2 \pm 0.3$ \\
& Maroua & $0.22 \pm 0.01$ & $9.01 \pm 0.30$ & $3.6 \pm 0.1$ \\
& Mokolo & $0.24 \pm 0.01$ & $9.40 \pm 0.30$ & $3.8 \pm 0.1$ \\
& Mora & $0.29 \pm 0.01$ & $9.10 \pm 0.30$ & $3.8 \pm 0.1$ \\
\hline Dakamji & Garoua & $0.23 \pm 0.02$ & $25.00 \pm 1.00$ & $2.3 \pm 0.1$ \\
& Maroua & $0.23 \pm 0.01$ & $21.30 \pm 1.00$ & $2.1 \pm 0.1$ \\
& Mokolo & $0.30 \pm 0.01$ & $21.20 \pm 1.00$ & $2.2 \pm 0.2$ \\
& Mora & $0.31 \pm 0.01$ & $20.70 \pm 1.00$ & $2.2 \pm 0.2$ \\
\hline \multicolumn{4}{c}{ DM: Dry Matter }
\end{tabular}

Biplot (axes F1 et F2 : 62,00\%)

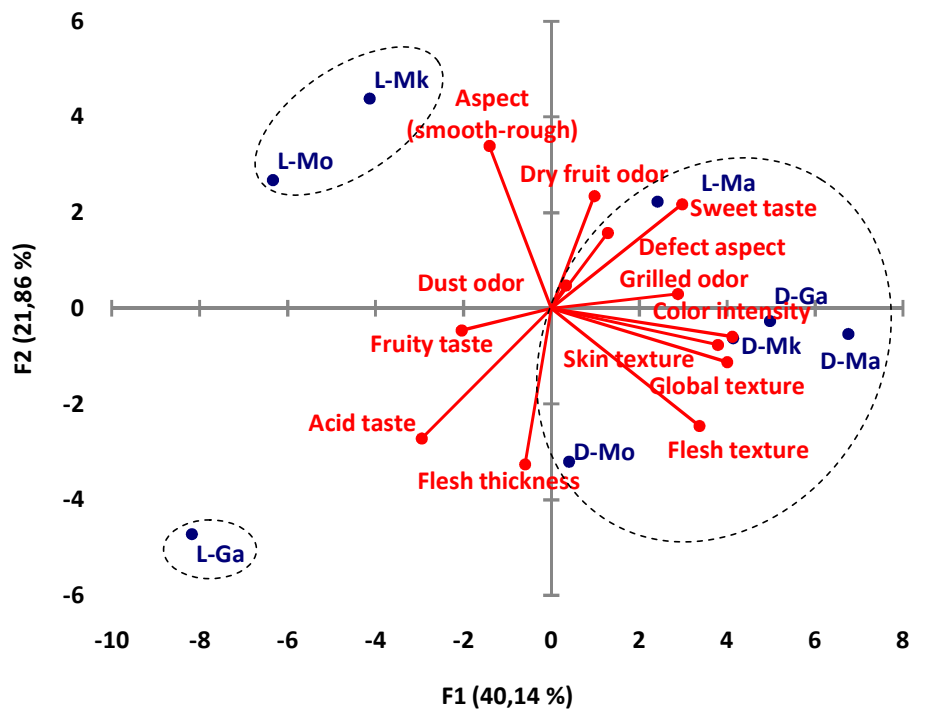

Fig. 2. Sensory attributes of Jaabi as affected by variety and origin of the fruits

(Ecotypes: $L=$ Lammuji; $D=$ Dakamji / $\underline{\text { Origins: }}$ Ga $=$ Garoua; $M a=$ Maroua; $M k=$ Mokolo; $M o=$ Mora)

From the observations above, Jaabi samples can be divided into 3 different clusters as evidenced on (Fig. 2): $\mathrm{C}_{1}$ (D-Ga, D-Ma, D-Mk, D-Mo and L$\mathrm{Ma}), \mathrm{C}_{2}(\mathrm{~L}-\mathrm{Ga})$ and $\mathrm{C}_{3}$ (L-Mk and L-Mo). One sample was chosen from clusters $\mathrm{C}_{2}$ and $\mathrm{C}_{3}$, and 2 samples from $\mathrm{C}_{1}$, for the consumer study. In this respect the samples chosen were: L-Ga, LMo, L-Ma, D-Ma and D-Mk.

Concerning Yaabande, the relationships between samples and their descriptors according to the sensory panel scoring (Fig. 4), indicates a clear difference between samples processed in the sun and samples processed otherwise (stifled or steamed). The sun processed samples constitute an isolated class compared to the other samples. Yaabande prepared by sunbaking is more granular both by tasting and by visual observation. This observation is evidenced by the sensory profiles of the samples (Fig. 5). Sun processed samples are characterized by high chewing texture and in mouth fineness, while cakes from steam and stifle baking are more firm in mouth.

The Yaabande cakes were divided in 3 clusters according to the sensory attributes (Table 6): $C_{1}$ (D-Ga-Vapor, L-Ga-Vapor), C 2 (D-Ma-Stifle, DMa-Vapor, D-Mk-Vapor, L-Ma-Vapor, L-MkVapor, Mix-Ga-Vapor) and $\mathrm{C}_{3}$ (D-Mo-Sun, L-MoSun). Four samples out of these classes were chosen for consumer test (D-Ga-Vapor, D-MaStifle, D-Mk-Vapor and L-Mo-Sun). The choice of 2 samples in C2 was due to the high density of this class. 
(a)

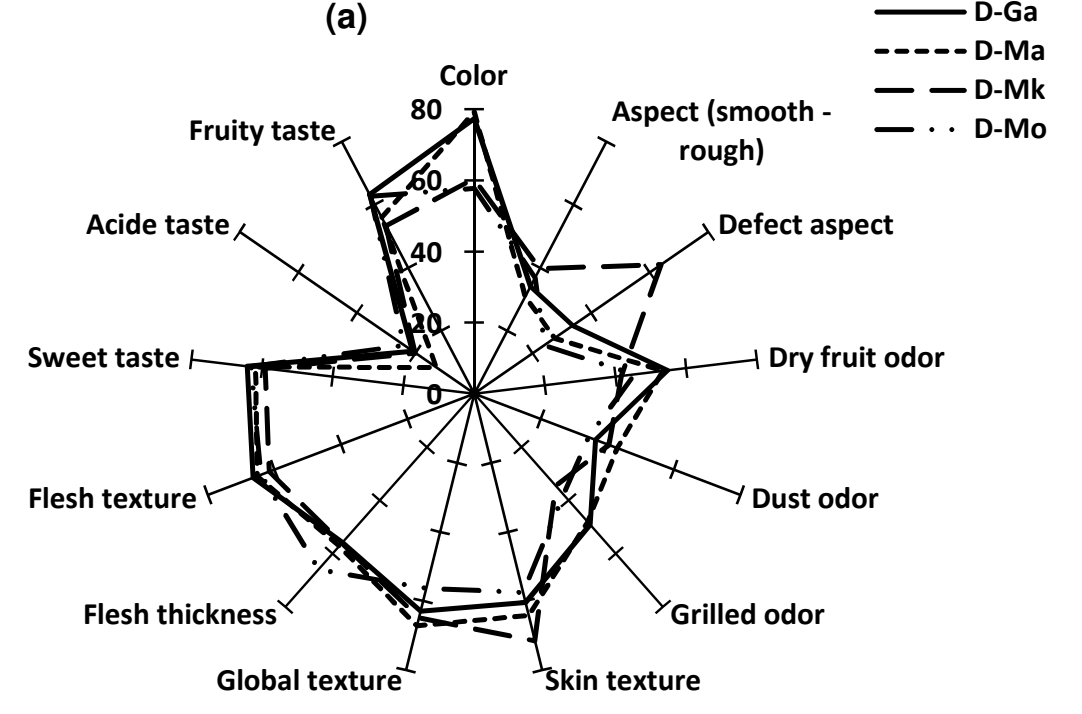

(b)

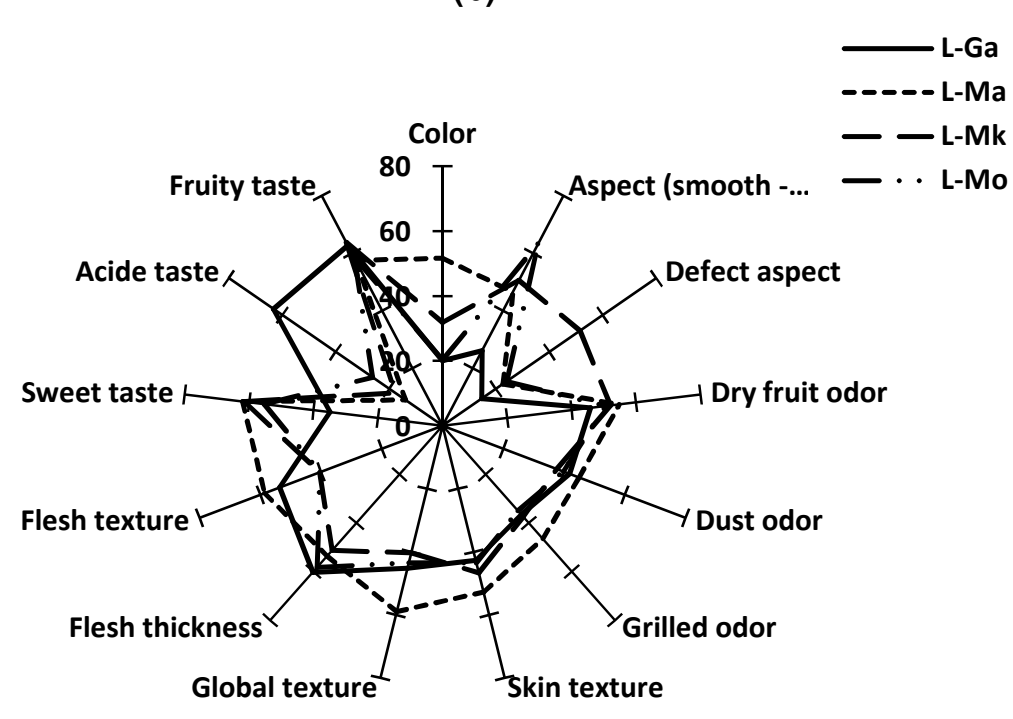

Fig. 3. Sensory profiles of Jaabi Dakamji (a) and Jaabi lammuji (b) as affected by origin of the product (Ecotypes: $L=$ Lammuji; $D=$ Dakamji ～ Origins: $G a=$ Garoua; $M a=$ Maroua; $M k=$ Mokolo; $M o=$ Mora) 
Table 4. Correlation table of sensory attributes of Jaabi Dakamji as perceived by panelists

\begin{tabular}{|c|c|c|c|c|c|c|c|c|c|c|c|c|c|c|c|c|}
\hline Variables & $\begin{array}{l}\text { Color } \\
\text { intensity }\end{array}$ & $\begin{array}{l}\text { Aspect } \\
\text { (smooth-rough) }\end{array}$ & $\begin{array}{l}\text { Defect } \\
\text { aspect }\end{array}$ & $\begin{array}{l}\text { Dry fruit } \\
\text { odor }\end{array}$ & $\begin{array}{l}\text { Dust } \\
\text { odor }\end{array}$ & $\begin{array}{l}\text { Grilled } \\
\text { odor }\end{array}$ & $\begin{array}{l}\text { Skin } \\
\text { texture }\end{array}$ & $\begin{array}{l}\text { Global } \\
\text { texture }\end{array}$ & $\begin{array}{l}\text { Flesh } \\
\text { thickness }\end{array}$ & $\begin{array}{l}\text { Flesh } \\
\text { texture }\end{array}$ & $\begin{array}{l}\text { Sweet } \\
\text { taste }\end{array}$ & $\begin{array}{l}\text { Acid } \\
\text { taste }\end{array}$ & $\begin{array}{l}\text { Fruity } \\
\text { taste }\end{array}$ & $\begin{array}{l}\text { Pulp } \\
\text { mass }\end{array}$ & $\begin{array}{l}\text { Sugar } \\
\text { content }\end{array}$ & $\begin{array}{l}\text { Titrable } \\
\text { acidity }\end{array}$ \\
\hline Color intensity & 1 & & & & & & & & & & & & & & & \\
\hline Aspect (smooth-rough) & -0.874 & 1 & & & & & & & & & & & & & & \\
\hline Defect aspect & -0.345 & 0.705 & 1 & & & & & & & & & & & & & \\
\hline Dry fruit odor & 0.934 & -0.906 & -0.611 & 1 & & & & & & & & & & & & \\
\hline Dust odor & 0.443 & -0.330 & 0.336 & 0.119 & 1 & & & & & & & & & & & \\
\hline Grilled odor & $\underline{0.954}$ & -0.911 & -0.572 & $\underline{0.998}$ & 0.179 & 1 & & & & & & & & & & \\
\hline Skin texture & -0.096 & 0.394 & 0.898 & -0.442 & 0.712 & -0.386 & 1 & & & & & & & & & \\
\hline Global texture & 0.649 & -0.384 & 0.380 & 0.334 & 0.919 & 0.392 & 0.683 & 1 & & & & & & & & \\
\hline Flesh thickness & -0.611 & 0.181 & -0.529 & -0.340 & -0.635 & -0.389 & -0.644 & -0.878 & 1 & & & & & & & \\
\hline Flesh texture & 0.756 & -0.818 & -0.780 & 0.940 & -0.209 & 0.917 & -0.714 & -0.007 & -0.048 & 1 & & & & & & \\
\hline Sweet taste & 0.389 & -0.527 & -0.823 & 0.691 & -0.616 & 0.644 & -0.923 & -0.446 & 0.306 & 0.895 & 1 & & & & & \\
\hline Acid taste & -0.706 & 0.688 & 0.060 & -0.473 & -0.912 & -0.521 & -0.369 & -0.860 & 0.542 & -0.186 & 0.249 & 1 & & & & \\
\hline Fruity taste & 0.068 & -0.205 & -0.691 & 0.411 & -0.851 & 0.354 & -0.925 & -0.697 & 0.474 & 0.690 & 0.938 & 0.568 & 1 & & & \\
\hline Pulp mass & -0.944 & 0.935 & 0.619 & -0.997 & -0.180 & -0.997 & 0.418 & -0.370 & 0.338 & -0.923 & -0.654 & 0.535 & -0.359 & 1 & & \\
\hline Sugar & 0.594 & -0.278 & -0.074 & $\overline{0.658}$ & -0.242 & $\overline{0.650}$ & -0.227 & 0.154 & -0.524 & 0.649 & 0.570 & 0.093 & 0.496 & -0.599 & 1 & \\
\hline Titratable acidity & -0.068 & 0.339 & 0.140 & 0.081 & -0.688 & 0.052 & -0.252 & -0.366 & -0.120 & 0.227 & 0.434 & 0.698 & 0.600 & 0.000 & 0.761 & 1 \\
\hline
\end{tabular}
Values in bold and underlined are significantly different from zero, $\alpha=0.05$ 
Table 5. Correlation table of sensory attributes of Jaabi Lammuji as perceived by panelists

\begin{tabular}{|c|c|c|c|c|c|c|c|c|c|c|c|c|c|c|c|c|}
\hline Variables & $\begin{array}{l}\text { Color } \\
\text { intensity }\end{array}$ & $\begin{array}{l}\text { Aspect } \\
\text { (smooth-rough) }\end{array}$ & $\begin{array}{l}\text { Defect } \\
\text { aspect }\end{array}$ & $\begin{array}{l}\text { Dry fruit } \\
\text { odor }\end{array}$ & $\begin{array}{l}\text { Dust } \\
\text { odor }\end{array}$ & $\begin{array}{l}\text { Grilled } \\
\text { odor }\end{array}$ & $\begin{array}{l}\begin{array}{l}\text { Skin } \\
\text { texture }\end{array} \\
\text { text }\end{array}$ & $\begin{array}{l}\text { Global } \\
\text { texture }\end{array}$ & $\begin{array}{l}\begin{array}{l}\text { Flesh } \\
\text { thickness }\end{array} \\
\end{array}$ & $\begin{array}{l}\begin{array}{l}\text { Flesh } \\
\text { texture }\end{array} \\
\end{array}$ & $\begin{array}{l}\text { Sweet } \\
\text { taste }\end{array}$ & $\begin{array}{l}\text { Acid } \\
\text { taste }\end{array}$ & $\begin{array}{l}\text { Fruity } \\
\text { taste }\end{array}$ & $\begin{array}{l}\text { Pulp } \\
\text { mass }\end{array}$ & $\begin{array}{l}\text { Sugar } \\
\text { content }\end{array}$ & $\begin{array}{l}\text { Titrable } \\
\text { Acidity }\end{array}$ \\
\hline Color intensity & 1 & & & & & & & & & & & & & & & \\
\hline Aspect (smooth-rough) & 0,064 & 1 & & & & & & & & & & & & & & \\
\hline Defect aspect & 0,138 & 0,398 & 1 & & & & & & & & & & & & & \\
\hline Dry fruit odor & 0,840 & 0,585 & 0,421 & 1 & & & & & & & & & & & & \\
\hline Dust odor & 0,593 & $-0,342$ & $-0,712$ & 0,220 & 1 & & & & & & & & & & & \\
\hline Grilled odor & 0,965 & $-0,105$ & $-0,115$ & 0,700 & 0,779 & 1 & & & & & & & & & & \\
\hline Skin texture & $\overline{0,997}$ & 0,133 & 0,149 & 0,873 & 0,578 & 0,955 & 1 & & & & & & & & & \\
\hline Global texture & 0,816 & $-0,129$ & $-0,458$ & 0,530 & 0,943 & $\frac{0,928}{0,928}$ & 0,810 & 1 & & & & & & & & \\
\hline Flesh thickness & $-0,670$ & $-0,345$ & $-0,828$ & $-0,796$ & 0,199 & $-0,459$ & $-0,677$ & $-0,119$ & 1 & & & & & & & \\
\hline Flesh texture & 0,561 & $-0,639$ & $-0,621$ & 0,061 & 0,929 & 0,751 & 0,521 & 0,843 & 0,152 & 1 & & & & & & \\
\hline Sweet taste & 0,648 & 0,746 & 0,626 & 0,950 & $-0,087$ & 0,450 & 0,690 & 0,243 & $-0,842$ & $-0,250$ & 1 & & & & & \\
\hline Acid taste & $-0,662$ & $-0,754$ & $-0,579$ & $-0,960$ & 0,042 & $-0,473$ & $-0,705$ & $-0,284$ & 0,815 & 0,221 & $-0,998$ & 1 & & & & \\
\hline Fruity taste & $-0,473$ & $-0,463$ & 0,463 & $-0,547$ & $-0,659$ & $-0,538$ & $-0,515$ & $-0,728$ & $-0,072$ & $-0,338$ & $-0,393$ & 0,446 & 1 & & & \\
\hline Pulp mass & $-0,940$ & 0,016 & $-0,402$ & $-0,784$ & $-0,351$ & $-0,853$ & $-0,927$ & $-0,598$ & 0,832 & $-0,421$ & $-0,651$ & 0,644 & 0,157 & 1 & & \\
\hline Sugar & $-0,581$ & $-0,797$ & $-0,116$ & $-0,863$ & $-0,259$ & $-0,491$ & $-0,637$ & $-0,493$ & 0,425 & 0,052 & $-0,832$ & 0,862 & 0,826 & 0,393 & 1 & \\
\hline Titratable Acidity & $-0,533$ & $-0,865$ & $-0,537$ & $-0,907$ & 0,109 & $-0,344$ & $-0,586$ & $-0,200$ & 0,712 & 0,336 & $-0,976$ & 0,982 & 0,497 & 0,488 & 0,900 & 1 \\
\hline
\end{tabular}

Values in bold and underlined are significantly different from zero, $\alpha=0.05$ 
Biplot (axes F1 et F2 : $82,71 \%$ )

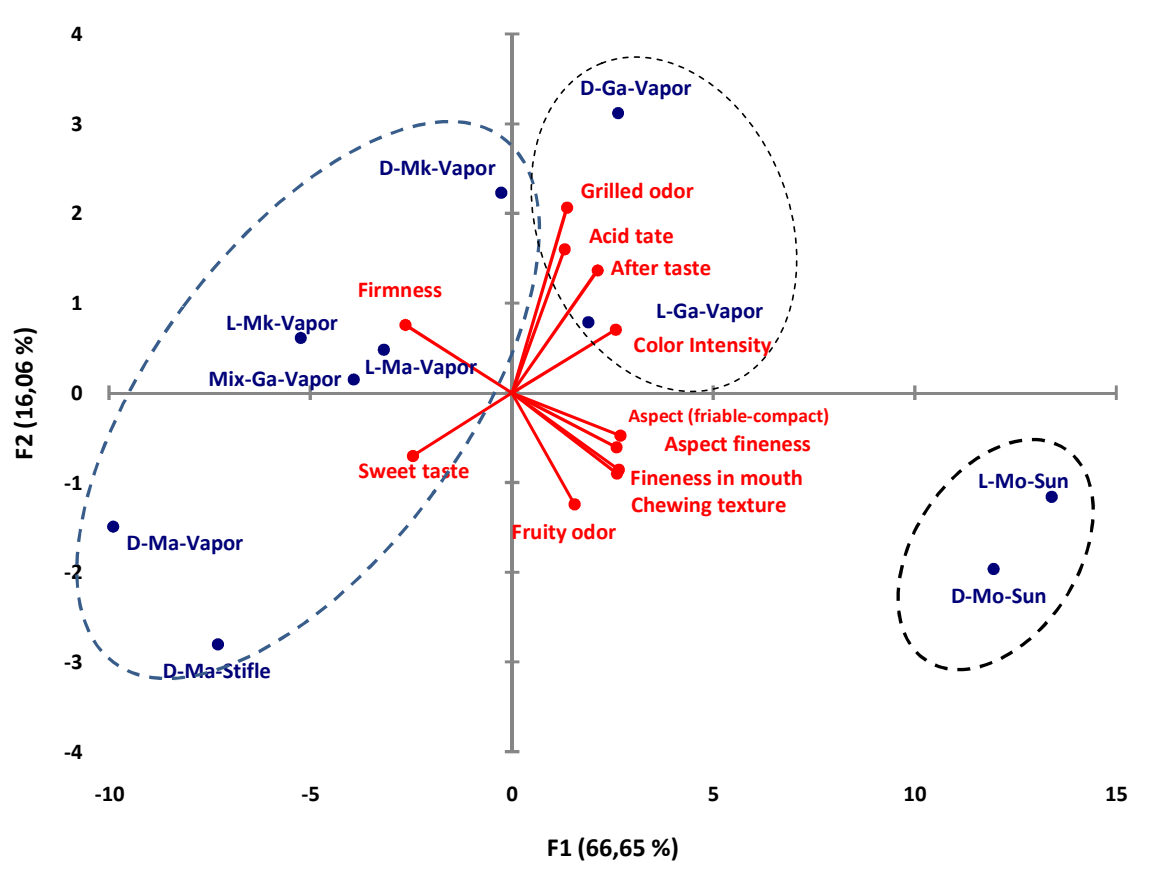

Fig. 4. Sensory attributes of Yaabande cake as affected by fruit variety, origin and processing method

(Ecotypes: $L=$ Lamouji; $D=$ Dakamji; Mix = mixture of varieties / Origins: Ga = Garoua; Ma = Maroua; $M k=$ Mokolo; Mo = Mora $/$ Processing method $:$ Vap = Steam cooking; Sun = Sun drying; Stifle = Stifle cooking)

\subsection{Consumer Testing}

\subsubsection{Consumer acceptance of Jaabi}

(Table 7) shows overall appreciation of Jaabi sample regarding appearance, taste and acceptability. It is noted that all samples are globally acceptable since the mean scores of acceptability and taste are greater than a score of 6 (slightly pleasant).

The three variables (appearance, taste and acceptability) are positively correlated as shown by the PCA on (Fig. 6) for African and NonAfrican consumers. It is noted that $97.31 \%$ and $99.75 \%$ of these relations are represented by the two first components (F1 \& F2) respectively for African and Non-African consumers. From the PCA plot, the homogeneous and nice appearance of $\mathrm{L}-\mathrm{Ga}$ is the main criteria of acceptability of this sample both by African and Non African consumers. On the other hand, African consumers preferred the taste of L-Mo, while Non Africans preferred D-Ma for the same attribute. Based on the answers of consumers concerning criteria of choice, the taste of the dry fruit appears as the main criteria by which Jaabi consumers choose their product (Fig. 7). This is normal since, before buying the fruit, consumer use to taste it. This taste has preferably to be sweet. In fact, up to $80 \%$ of consumers prefer sweet Jaabi as shown on (Fig. 8). The same figure indicates that appearance of the fruit is characterized by its color which should be either red or Yellow, while on eating, the pulp should preferably be floury.

Table 6. Main classes of Yaabande cake based on sensory attributes

\begin{tabular}{lll}
\hline \multicolumn{3}{c}{ Classes } \\
\hline $\mathbf{1}$ & $\mathbf{2}$ & $\mathbf{3}$ \\
\hline D-Ga-Vapor & D-Ma-Stifle & D-Mo-Sun \\
L-Ga-Vapor & D-Ma-Vapor & L-Mo-Sun \\
& D-Mk-Vapor & \\
& L-Ma-Vapor & \\
& L-Mk-Vapor & \\
& Mix-Ga-Vapor & \\
\hline
\end{tabular}



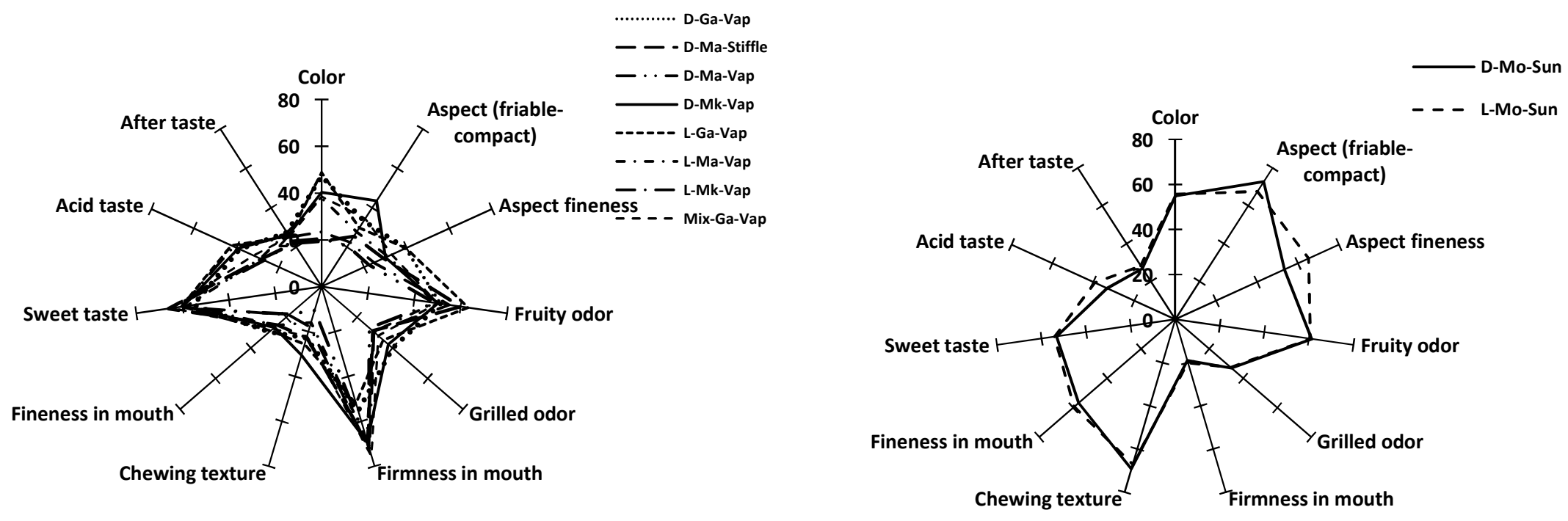

Fig. 5. Sensory profiles of Yaabande as affected by processing methods

(Ecotypes: L= Lamouij; D= Dakamii; Mix = mixture of varieties / Origins: Ga = Garoua; $M a=$ Maroua; Mk = Mokolo ; Mo = Mora $/$ Processing method $:$ Vap = Steam cooking Sun $=$ Sun drying ; Stifle $=$ Stifle cooking) 
Biplot (axes F1 et F2 : $97,31 \%$

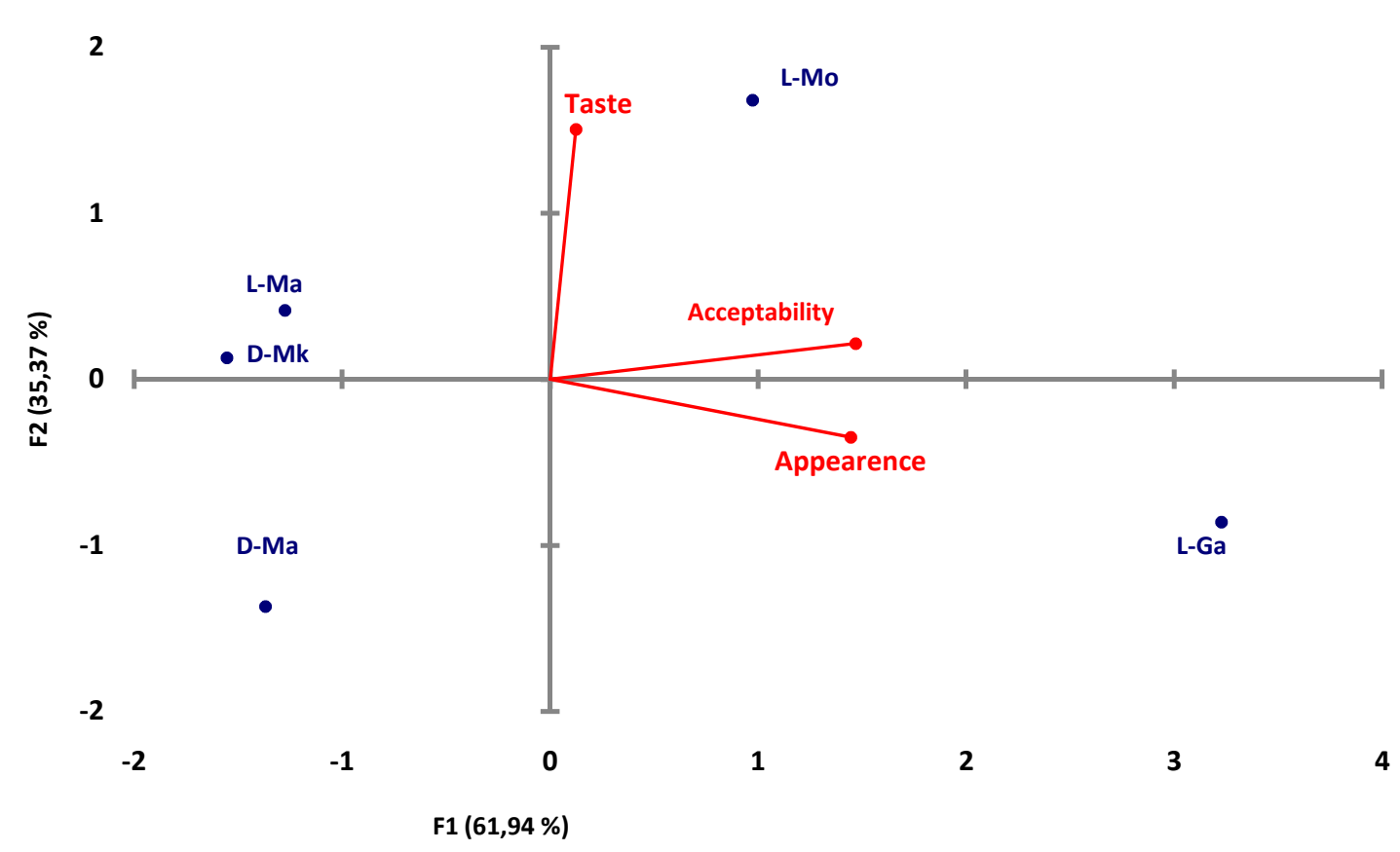

(B)

Biplot (axes F1 et F2 : $99,75 \%$

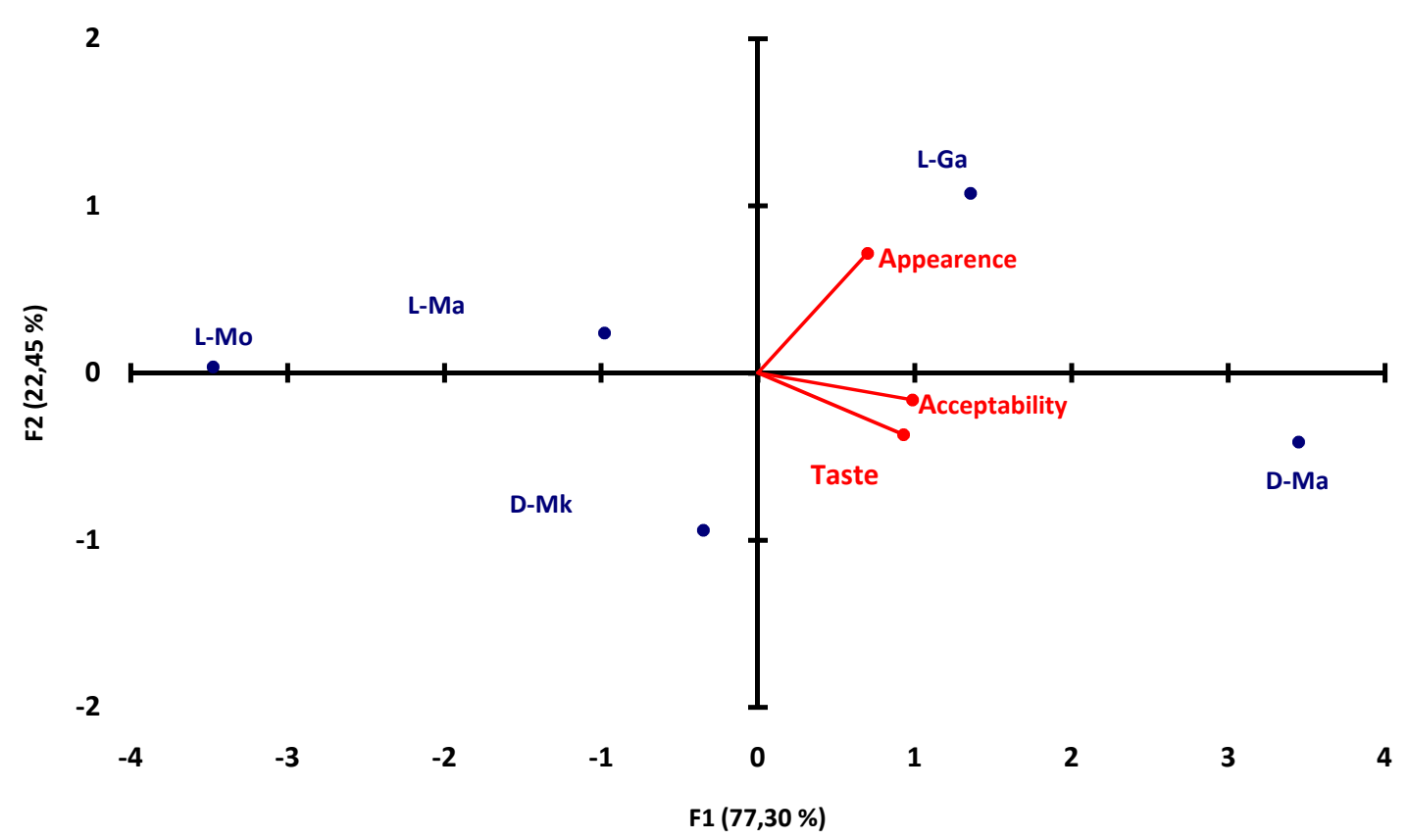

Fig. 6. Relationship between appearance, taste and acceptability of Jaabi samples as perceived by African (A) and non-African (B) consumers 
Based on these data, African and non African consumers, do not prefer Jaabi in the same way (Fig. 9). Africans accept almost at equal level, all samples from different origin, though the L-Ga is preferred for its appearance. On the contrary, non African consumers have a clear preference for D-Ma, apparently for its taste, L-Ga appearing as a second choice for its appearance. The other samples appear as not preferred by these consumers. In fact, the small number of non Africans involved in the consumption test may constitute a limit for the significance of the data obtained, since, on the other hand, many of them discovered the product during the test, while Africans consumers are used to it.

\subsubsection{Consumer acceptance of Yaabande}

Globally, all Yaabande samples are acceptable and considered as pleasant, since scores are close to 7 (pleasant) (Table. 8). This acceptability is highly correlated to the taste and the appearance of the product for African consumers, while for Non African consumers, it is mainly correlated to taste only (Fig. 10).

Yaabande taste, as perceived by consumers, includes, out of the sweetness, in mouth sensations on eating since, from the question related to global preference attributes of the product, consumers reply by texture attributes (Fig. 11). In this respect, Yaabande cake should preferably have a yellowish aspect, a crumbly texture in mouth, and a floury flesh.

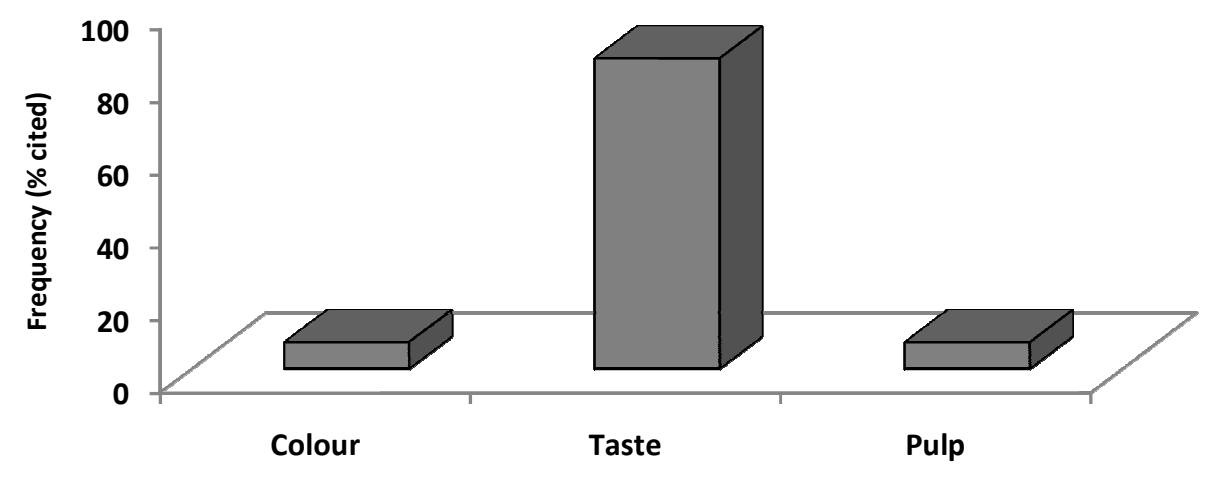

Criteria of choice

Fig. 7. Criteria of choice by Jaabi consumers

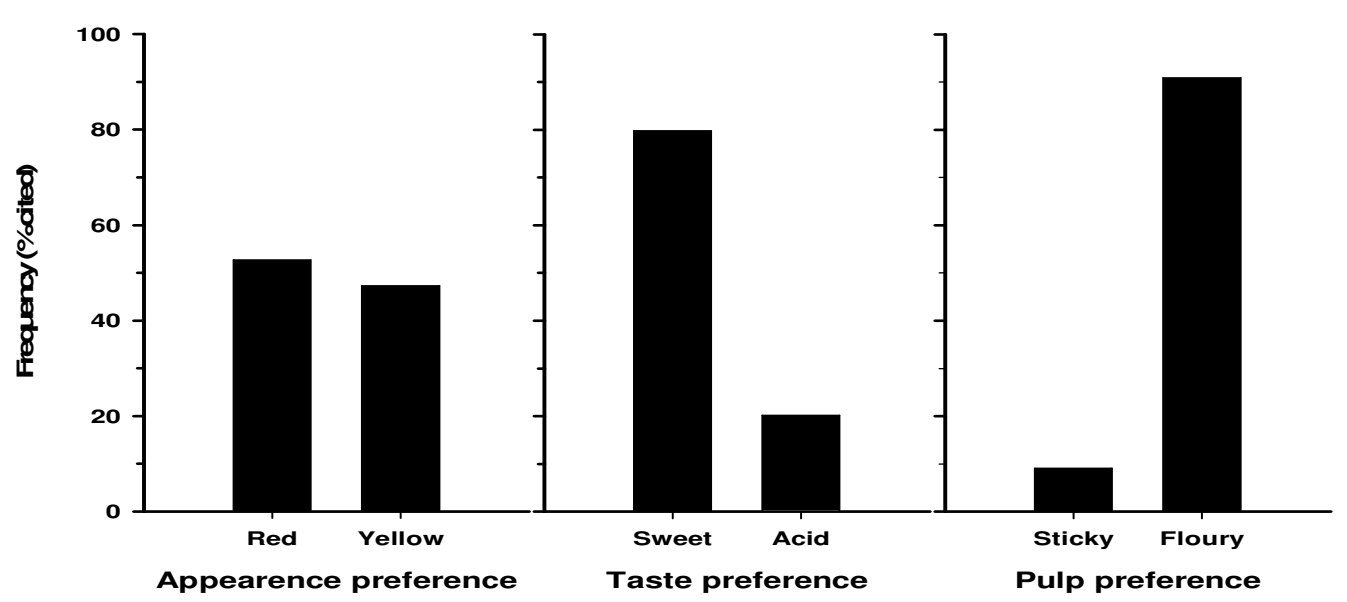

Fig. 8. Consumer preference of Jaabi related to appearance, taste and pulp characteristics of the dry fruit 


\section{(A) African consumers}

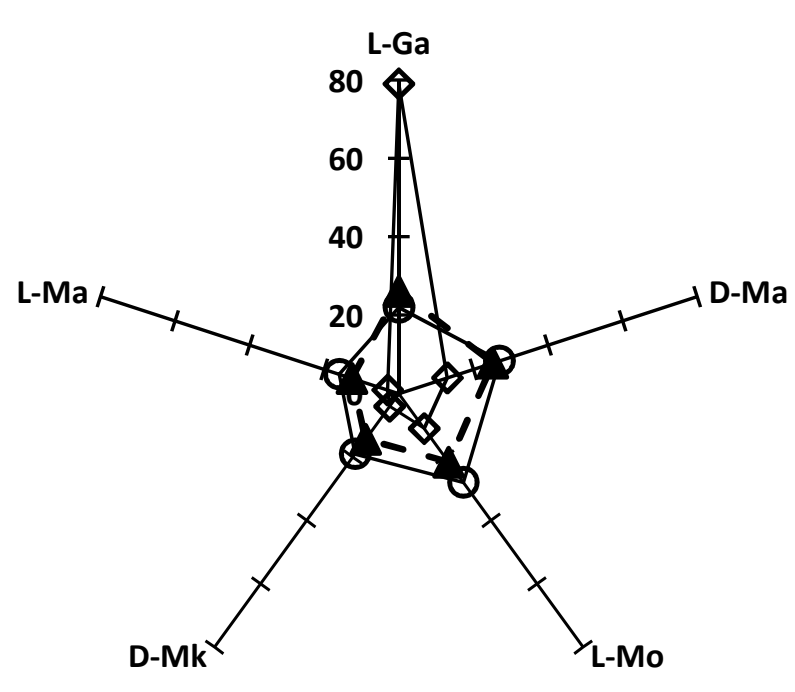

(B) Non African consumers

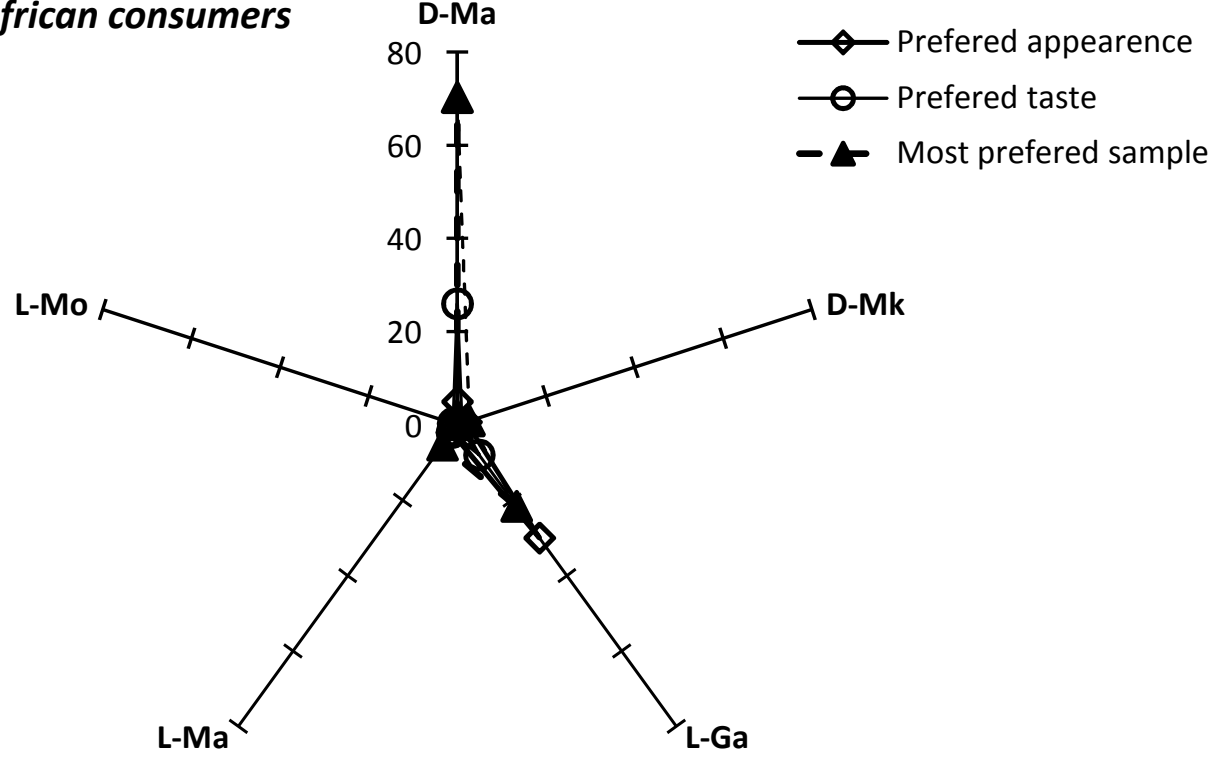

Fig. 9. Preference and acceptance of Jaabi by African and non African consumers as affected by the origin of the product 
Touwang et al.; JSRR, 4(7): 635-651, 2015; Article no.JSRR.2015.067

African consumers

Biplot (axes F1 et F2 : 99,97\%)

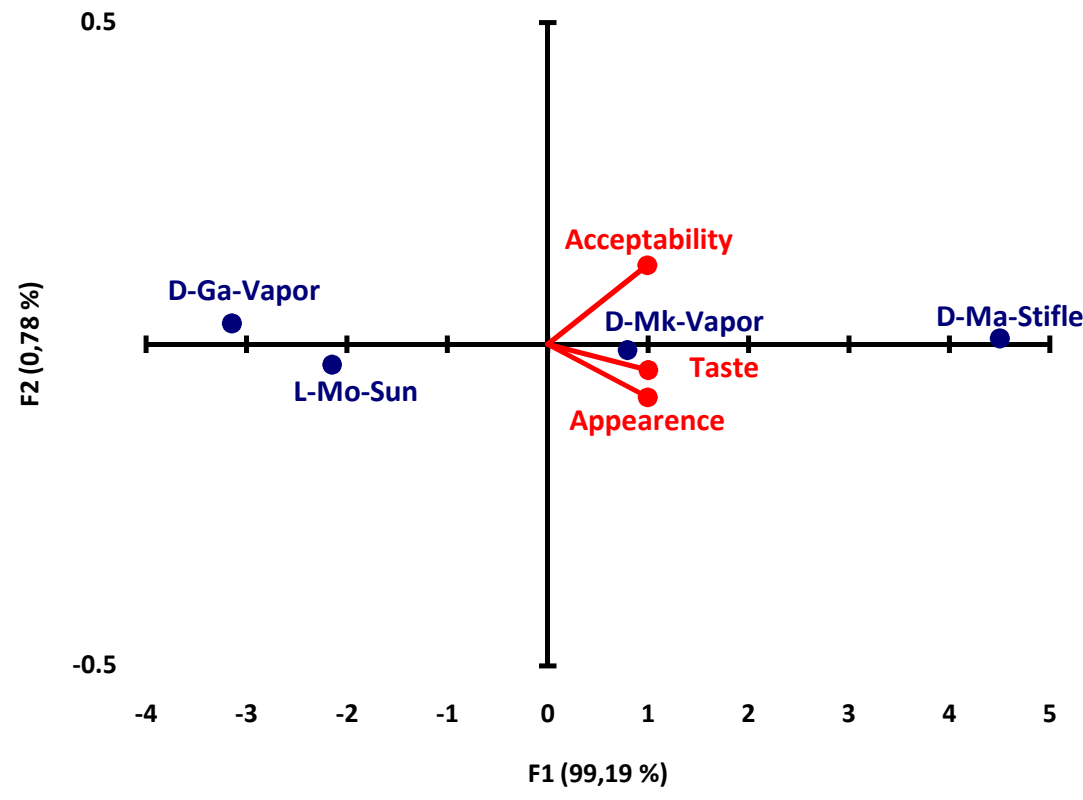

Non African consumers

Biplot (axes F1 et F2 : 99,84 \%)

1

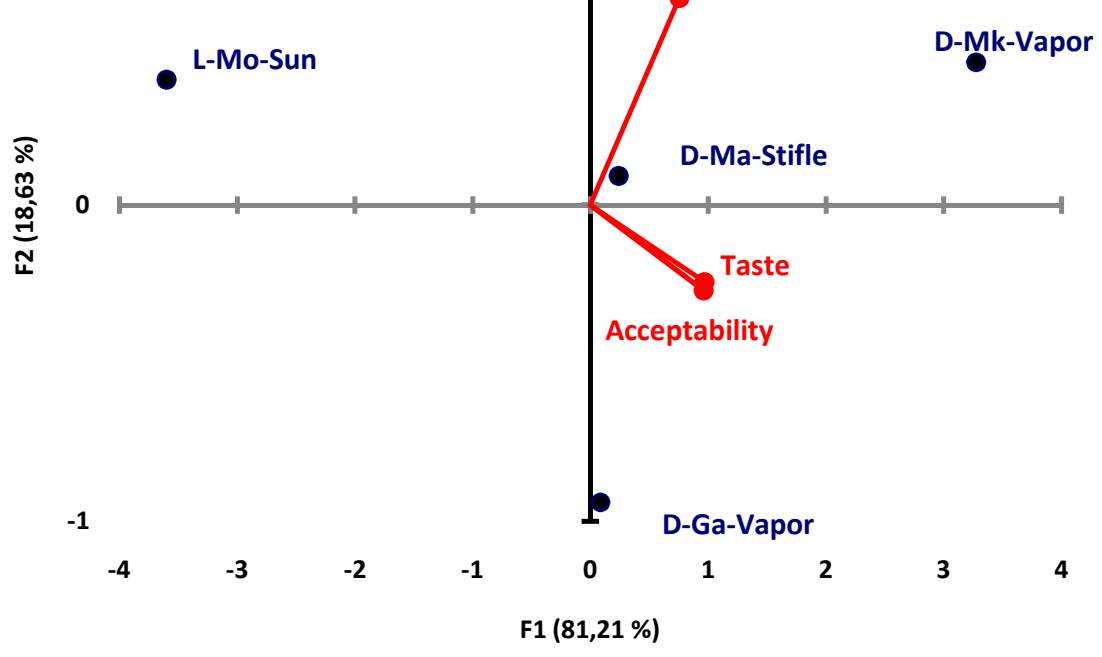

Fig. 10. Relationship between appearance, taste and acceptability of Yaabande samples as perceived by African and Non-African consumers

649 


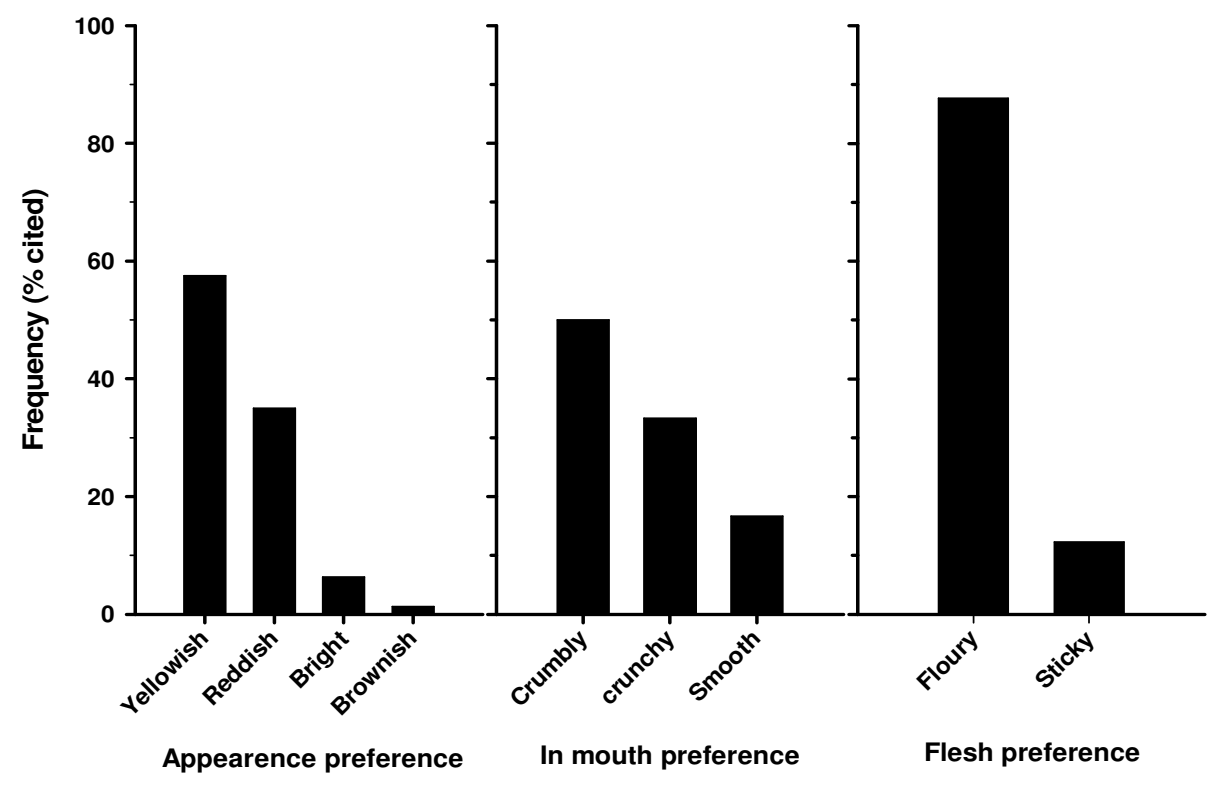

Fig. 11. Consumer preference of Yaabande related to appearance, in mouth and flesh characteristics of the product

Table 7. Mean overall scores of Jaabi

\begin{tabular}{llll}
\hline Samples & Appearance & Taste & Acceptability \\
\hline D-Ma & $5,7 \pm 1,8$ & $6,2 \pm 2,0$ & $6,3 \pm 1,9$ \\
D-Mk & $5,7 \pm 1,6$ & $6,3 \pm 1,7$ & $6,2 \pm 1,6$ \\
L-Ga & $7,8 \pm 1,3$ & $6,2 \pm 1,9$ & $6,5 \pm 1,7$ \\
L-Ma & $5,8 \pm 1,5$ & $6,4 \pm 1,7$ & $6,3 \pm 1,6$ \\
L-Mo & $6,2 \pm 1,7$ & $6,5 \pm 1,6$ & $6,4 \pm 1,5$ \\
\hline
\end{tabular}

Table 8. Mean overall scores of Yaabande

\begin{tabular}{llll}
\hline Samples & Appearance Taste & Acceptability \\
\hline D-Ga-Vapor & $6,0 \pm 1,5$ & $6,2 \pm 1,7$ & $6,4 \pm 1,5$ \\
D-Ma-Stifle & $7,1 \pm 1,7$ & $7,2 \pm 1,5$ & $7,2 \pm 1,5$ \\
D-Mk-Vapor & $6,8 \pm 1,5$ & $6,9 \pm 1,3$ & $6,9 \pm 1,2$ \\
L-Mo-Sun & $6,2 \pm 1,4$ & $6,0 \pm 1,8$ & $6,0 \pm 1,7$ \\
\hline
\end{tabular}

\section{CONCLUSION}

This study shows that the taste of Jaabi and Yaabande is the main sensory attribute governing the consumption of these products. All Jaabi and Yaabande samples are globally acceptable by African consumers, whatever the origin and the variety. Meanwhile, it should be noted that throughout the study, no reference was made by consumers to the aroma complex and therapeutic properties of the products. Thus, the market development of Jaabi and resulted products is just based on proposing a product presenting original taste of the product. In this respect, standardizing the process procedures appears as an option for the market development. Associated to this option, it should be interesting to determine physico-chemical compounds which build up the taste of the products.

\section{ACKNOWLEDGEMENT}

This publication is an output of AFTER (African Food Tradition rEvisited by Research) project, funded by European Union (FP7 no 245-025) (AFTER, http://www.after-fp7.eu), and of AIRD (Agence Inter-Etablissements de Recherche pour le Développement), in the framework of the research team TQI2A (Technologie, Qualité et Innovations Agro Alimentaires)

\section{COMPETING INTERESTS}

Authors have declared that no competing interests exist.

\section{REFERENCES}

1. Azam-Ali S, Bonkoungou E, Bowe C, deKock C, Godara A, and Williams JT. Ber and other jujubes, ed. by Williams JT, Smith RW, Haq N, Dunsiger Z. International Centre for Underutilised Crops, University of Southampton, Southampton, UK. 2006;302. 
2. Noyé D. Fulfulde -French dictionary. Dialette Peul Diamaré. Northern Cameroon. Genthner P. Paris / procure des missions, Garoua, Cameroun. 1989;425.

3. Dairou S, Biyanzi P, Pallet D, Ndjouenkeu R. Traditional production, processing and quality attributes of Ziziphus mauritiana in Savannah Region of Cameroon. Journal of Scientific Research \& Reports. 2014;3(5):686-699.

4. Andreasen AR, Ratchford BT. Factors affecting consumers' use of information sources. Journal of Business Research. 1976;4(3):197-212.
5. Meilgaard M, Civile GV, Carr BT. Sensory Evaluation Techniques 4th Edition, CRC Press, Florida, USA; 2007.

6. Tomlins KI, Owori C, Bechoff A, Menya G, and Westby A. Relationship among the carotenoids content, dry matter content and sensory attributes of sweet potato. Food Chemistry. 2012;131:14-21.

7. AFNOR (Association Française de Normalisation), Collection of French standards of products derived from fruits and vegetables. Jus de fruits. 1ére édition. Paris (France). 1982;327.

8. Fischer E, Stein EA. DNS colorimetric determination of available carbohydrates in foods. Biochemical Preparation. 1961;8:30 $-37$.

(C) 2015 Touwang et al.; This is an Open Access article distributed under the terms of the Creative Commons Attribution License (http://creativecommons.org/licenses/by/4.0), which permits unrestricted use, distribution, and reproduction in any medium, provided the original work is properly cited.

Peer-review history:

The peer review history for this paper can be accessed here: http://www.sciencedomain.org/review-history.php?iid=746\&id=22\&aid=6996 